\title{
Effect of organic and inorganic fertilizers on regeneration of seedlings of Ricinodendron heudelotii (Baill) Pierre et Pax.
}

\author{
Grace Mendi ANJAH ${ }^{1 *}$, Fritz Oben $\mathrm{TABI}^{2}$ and Antoine MVONDO ZE ${ }^{2}$ \\ ${ }^{1}$ Department of Plant Biology, University of Dschang, P.O. Box 67, Dschang. Cameroon. \\ ${ }^{2}$ Department of Soil Sciences, University of Dschang, P.O. Box 222, Dschang. Cameroon. \\ *Corresponding author; E-mail: ngracemendi@yahoo.com
}

\begin{abstract}
Most soils in the humid tropical zones present a particular problem. Due to leaching, the fertilizer provided by the process of nutrient cycling in tropical rainforest is confined to the top few inches of the soil. Varying quantities of manure and NPK fertilizers were applied to assess their effects on the growth of Ricinodendron heudelotii seedlings, a non-timber-forest-product. Assessment was done by measurements of height, number of leaves, leaf area, seedling biomass, the relative growth rate, and the net assimilation rate. The effects of organic and inorganic fertilizers on plant height and number of leaves were not significant, though their effect on leaf area was significant $(\mathrm{p}<0.05)$. The total biomass, relative growth rate, and net assimilation rate under the different treatment combinations had no significant effect on yield. However, fertilizer treatments had a significant effect among the periods of application for the biomass and the net assimilation rate $(\mathrm{p}<0.05)$, but had no significant effect on the observation period for the relative growth rate.

(c) 2015 International Formulae Group. All rights reserved.
\end{abstract}

Keywords: Manure, NPK, non-timber-forest-product, biomass, relative growth rate, net assimilation rate.

\section{INTRODUCTION}

As the world grapples with the challenge of feeding an ever growing population in the face of dwindling natural resources, confounded by climate change, findings show that science-based farming methods integrating the systematic use of fertilizer by farmers can significantly reduce the need to clear forested lands (Bernard, $2015)$. With the reduction by about $18 \%$ of the original forest which stretched from Guinea to Cameroon, and the tripling of populations in these countries, there is absolutely no room for expansion. Thus, strategies to reduce deforestation and conserve biodiversity focuses on fertilizer-for-forest projects which is based on increasing crop production with little or no effect on the environment.

The soils of these forest areas are mostly deficient in phosphorus, calcium and magnesium. Potassium rarely exceeds an average of $0.15 \mathrm{cmol} / \mathrm{kg}$ and the total nitrogen content is low because of rapid chemical reactions with organic matter (Bernard, 2015). Soils in these virgin forests are the poorest in these mineral needs, with deeper layers of soils requiring costly management crops and trees to do well.

Deborah (2001), in experimenting with seedlings and cuttings of four tree species to 
determine their response to nitrogen and phosphorus fertilization, observed that $\mathrm{P}$, rather than $\mathrm{N}$, limits seedling performance and may ultimately influence tree diversity in young secondary tropical forests.

In another study by Lumu et al. (2013) to evaluate the effects of different soils on the growth of pine seedlings and to compare the performance of seedlings provided with different fertilizer formulations and amounts, observed after 3 months that, NPK formulations of 17-17-17 had the best mean height and mean girth at level $0.5 \mathrm{~kg}$ with $(16.75,0.23 \mathrm{~cm})$ respectively, compared with fertilizer formulations of 18-4-14 and 25-5-5 with $(13.42 \mathrm{~cm}, 0.175 \mathrm{~cm})$ and $(12.44 \mathrm{~cm}$, $0.174 \mathrm{~cm}$ ) respectively.

In an attempt to evaluate the effects of organic and inorganic fertilizer on yield of cowpea, Taura and Fatima (2008) showed that, the combination of organic manure and inorganic fertilizer yielded higher than either organic manure or inorganic fertilizer applied separately.

Ndubuaku and Kassim (2012) investigated the effect of organic fertilizers on the field establishment of Amazon cocoa seedlings. Results showed that the highest rate of leaf emergence on the seedlings were seedlings treated with poultry manure, followed by green manure, urea and superphosphate. Stem height, stem diameter, leaf number and leaf area of seedlings increased with the application of all fertilizers. By 32 weeks after planting, the poultry manure and green manure treatment plants were significantly $(p=0.05)$ larger than those of urea and single superphosphate treatments.

Catalina et al. (2010) however, in the production and vegetative growth of coffee trees under fertilization, observed that there was no effect of fertilizer on leaf area, number of leaves, and number of nodes per branch and yield.

Ricinodendron heudelotii is a species of the family Euphorbiaceae. 'Njanssang', as it is commonly called in the English-speaking part of Cameroon, has typically become a species of the fringing gaps at forest edges and in secondary scrub and thickets (ICRAF, 2004). It is mostly found in the deciduous forest with compound-digitate leaves having 3 to 5 leaflets, and scaly brownish bark with granular reddish slash. It is a large tree reaching $45 \mathrm{~m}$ in height and $150 \mathrm{~cm}$ in diameter, its crown is spherical with a straight bole although sometimes twisted. The tree is a heliophyte and in areas where preserved such as on farmlands, it is fast-growing, requiring no shading (Anjah and Oyun, 2009). Tchoundjeu and Atangana (2006) identified Ricinodendron heudelotii as a Non Wood Forest Product (NWFP).

\section{MATERIALS AND METHODS Fertilizer application}

Polyethylene bags of $15 \times 14 \mathrm{~cm}$ layflat were filled with forest topsoil, divided into four lots of 20 bags each and labelled P1, P2, $\mathrm{P} 3$, and P4. P1 was the control with no treatment applied; P2 (treatment 2), was compost of .04 $\mathrm{g}$ applied to each potted seedling; P3 (treatment 3), where NPK 20:10:10 only was applied at $.04 \mathrm{~g}$ to each potted seedling. P4 lot constituted the fourth treatment combination comprising a combination of $.02 \mathrm{~g}$ of compost and a $.02 \mathrm{~g}$ of NPK 20:10:10. Watering was done on a daily basis. The experiment was a completely randomised design.

\section{Data collection}

The parameters measured on a 3weekly basis included (i), plant height, (ii), the number of leaves, (iii), the leaf area, (iv), the seedling biomass, (v), the relative growth rate (RGR), and (vi), the net assimilation rates (NAR).

The plant heights were measured with the use of a metre rule while the number of leaves was determined by counting. Measurement of seedling biomass was by uprooting four seedlings from soil using a soil fork to ensure that no roots were destroyed. The selection of the seedlings was based on tables of random numbers 3 weeks after the treatments. Each seedling was separated into root and shoot components after carefully 
rinsing the roots in water and allowing to dry for a few minutes using the procedure of Oni and Gbadamasi (1998). Each group of plants were weighed using an electronic balance, put in envelopes according to their root-shoot components and taken to the Soil and Environment Laboratory of the University of Dschang for biomass measurements. In the laboratory, the different envelopes were put in an oven maintained at $50{ }^{\circ} \mathrm{C}$, for 48 hours. When these were removed, the biomass was calculated as follows;

$\mathrm{BP}=(\mathrm{Ldw}+\mathrm{Sdw})+\mathrm{Rdw}$

Where;

$\mathrm{BP}=$ Biomass Produced, $(\mathrm{Ldw}+\mathrm{Sdw})=$ (Leaf dry weight + Shoot dry weight),

$\mathrm{Rw}=$ Root dry weight.

The Relative Growth Rate (RGR) and the Net Assimilation Rate (NAR) were calculated;

$\mathrm{RGR}=\mathrm{InW} 2-\mathrm{InW} 1 / \mathrm{t} 2-\mathrm{t} 1 \mathrm{in}(\mathrm{gm} / \mathrm{t})$.

$\mathrm{NAR}=\mathrm{W} 2-\mathrm{W} 1 / \mathrm{A} 2-\mathrm{A} 1 \mathrm{X}$ InA2 - InA1 / $\mathrm{t} 2-\mathrm{t} 1 \mathrm{in} \mathrm{gm} / \mathrm{gm} / \mathrm{t}$.

Where;

$\mathrm{A}=$ Leaf Area; $\mathrm{W} 2$ = Final dry weight; $\mathrm{W} 1$ = Initial dry weight; $\mathrm{t} 2=$ Final harvest time; $\mathrm{t} 1$ = Initial harvest time; $\ln =$ natural logarithmic $(\log \mathrm{i})$.

\section{Statistical analysis}

The analysis of variance (ANOVA) was used to examine the differences among treatments. Mean separation was by method of LSD at 5\% probability.

\section{RESULTS}

\section{Soil properties}

The results of soil analysis indicate that for the forest site, organic carbon content was $3.8 \%, \mathrm{C} / \mathrm{N}$ ratio of $40,2.8 \mathrm{cmol} / \mathrm{kg}^{-1} \mathrm{Ca}, 0.68$ $\mathrm{cmol} / \mathrm{kg}^{-1} \mathrm{Mg}, 0.18 \mathrm{cmol} / \mathrm{kg}^{-1} \mathrm{~K}, 18 \%$ base saturation, $6.2 \mathrm{mg} / \mathrm{kg}^{-1}$ Bray II $\mathrm{P}, \mathrm{pH}$ of 4.7 and $0.97 \%$ total $\mathrm{N}$.

\section{Plant height/number of leaves/leaf area}

Table 1 shows the cumulative values in plant height, number of leaves and leaf area for the period of 15 weeks. The values indicate that there was a gradual increase in all the parameters under each organic and inorganic treatment combination. However, the mean values for the plant height, number of leaves and leaf area shown on Table 2 are variable.

\section{Plant height}

Analysis of variance results show that for plant height, there were no significant differences among the fertilizer treatments. Figure 1 shows a gradual increase in plant height from the first week of all treatments application to the last.

\section{Number of leaves}

There were no significant differences in leaf number among the fertilizer treatments. However, Figure 2 shows a gradual increase in leaf number from the $1^{\text {st }}$ to the $4^{\text {th }}$ period of application though this differed for the combined Compost-NPK treatment.

\section{Leaf area}

The differences among mean values for leaf area were significant $(\mathrm{p}<0.05)$. LSD to test the means among the leaf area values indicate that the means of the organic and inorganic (compost + NPK) treatment combination, were significantly different $(\mathrm{p}>$ 0.05) from those of NPK only, compost only, and control with no fertilizer (Table 3). Figure 3 also shows a gradual increase in leaf area bars per period of fertilizer treatment applications.

\section{Total biomass}

The highest biomass at 3 WAP (18.9 g), 6 WAP (25.98 g), 9 WAP (44.05 g), 12 WAP (55.18 g) and 15 WAP (54.92 g) were obtained under combined application of compost and NPK fertilizers (Table 4). They were however not significantly different.

\section{Relative growth rate}

It was observed that the highest (0.39) relative growth rate was recorded in weeks 36 under treatment T1. The lowest was also recorded under $\mathrm{T} 1$ between $0-3$ weeks. These results presented in Table 5 show no significant differences. 


\section{Net assimilation rate}

Table 6 shows a summary of the net assimilation rates for all the treatment combinations. The rates were variable between period and among treatments. No consistent pattern could be observed. Figures 4, 5 and 6 are histograms of both fresh and dry biomass increases on weekly basis.

\section{Analysis of variance}

Table 7 shows the mean values of total biomass weight (shoot + root dry weights), the net assimilation rate (NAR), and the relative growth rates (RGR) for $R$. heudelotii seedlings under different fertilizer treatment combinations. Table 8 shows that fertilizer treatments had a significant effect only among the periods for the biomass and the NAR but had no significant effect on the period for the RGR.

Table 1: Summary of cumulative growth values of $R$. heudelotii under fertilizer combinations.

\begin{tabular}{lcccc}
\hline Fertilizer treatments & $\begin{array}{c}\text { Period of } \\
\text { observation } \\
\text { (weeks) }\end{array}$ & Height (cm) & $\begin{array}{c}\text { Number } \\
\text { of leaves }\end{array}$ & Leaf area $\left.\mathbf{c m}^{2}\right)$ \\
\hline Absolute control (T1) & 3 & $10.75 \pm .33$ & $2 \pm .01$ & $25.63 \pm .25$ \\
Sole compost (T2) & 3 & $10.25 \pm .25$ & $2 \pm .11$ & $25.38 \pm .35$ \\
NPK (20 10 10) (T3) & 3 & $11.13 \pm .23$ & $2 \pm .13$ & $26.16 \pm .33$ \\
NPK + Compost (T4) & 3 & $11.81 \pm .25$ & $2 \pm .01$ & $25.75 \pm .23$ \\
\hline Absolute control (T1) & 6 & $15.38 \pm .35$ & $4.25 \pm .11$ & $24.00 \pm .21$ \\
Sole compost (T2) & 6 & $15.75 \pm .33$ & $5.75 \pm .13$ & $60.75 \pm .22$ \\
NPK (20 10 10) (T3) & 6 & $15.88 \pm .25$ & $5.75 \pm .02$ & $72.13 \pm .23$ \\
NPK + Compost (T4) & 6 & $16.00 \pm .22$ & $5.50 \pm .21$ & $42.50 \pm .12$ \\
\hline Absolute control (T1) & 9 & $19.25 \pm .31$ & $6.00 \pm .12$ & $32.75 \pm .31$ \\
Sole compost (T2) & 9 & $21.13 \pm .33$ & $7.50 \pm .22$ & $83.00 \pm .21$ \\
NPK (20 10 10) (T3) & 9 & $20.50 \pm .25$ & $7.50 \pm .31$ & $69.25 \pm .22$ \\
NPK + Compost (T4) & 9 & $20.00 \pm .24$ & $7.50 \pm .15$ & $64.25 \pm .12$ \\
\hline Absolute control (T1) & 12 & $25.25 \pm .31$ & $6.00 \pm .02$ & $37.00 \pm .01$ \\
Sole compost (T2) & 12 & $30.00 \pm .25$ & $9.25 \pm .12$ & $100.00 \pm .21$ \\
NPK (20 10 10) (T3) & 12 & $27.25 \pm .15$ & $8.75 \pm .33$ & $86.25 \pm .25$ \\
NPK + Compost (T4) & 12 & $28.25 \pm .31$ & $9.75 \pm .25$ & $99.50 \pm .05$ \\
\hline Absolute control (T1) & 15 & $29.67 \pm .22$ & $6.67 \pm .25$ & $40.00 \pm .24$ \\
Sole compost (T2) & 15 & $34.00 \pm .13$ & $8.25 \pm .16$ & $103.00 \pm .02$ \\
NPK (20 10 10) (T3) & 15 & $31.50 \pm .24$ & $7.25 \pm .23$ & $90.00 \pm .15$ \\
NPK + Compost (T4) & 15 & $34.50 \pm .33$ & $8.25 \pm .22$ & $117.00 \pm .23$ \\
\hline
\end{tabular}

Table 2: Mean values of plant height, number of levels and leaf area of $R$. heudelotii plants that received NPK and compost.

\begin{tabular}{lccc}
\hline Treatment & Plant height $(\mathbf{c m})$ & Number of leaves & Leaf areas \\
\hline C+NPK & $34.5 \pm .25$ & $8.3 \pm .35$ & $117.0 \pm .51$ \\
C & $34.0 \pm .56$ & $8.3 \pm 1.2$ & $103.0 \pm .03$ \\
NPK & $31.5 \pm .51$ & $7.3 \pm 1.5$ & $90.0 \pm .35$ \\
-C-NPK & $29.9 \pm .5$ & $6.7 \pm 2.5$ & $40.0 \pm .05$ \\
\hline
\end{tabular}


Table 3: Follow-up means effect for leaf area.

\begin{tabular}{lc}
\hline Fertilizer & Mean leaf Area $\left(\mathbf{c m}^{\mathbf{2}}\right)$ \\
\hline C + NPK & $40.00 \mathrm{a} \pm .05$ \\
NPK & $90.00 \mathrm{~b} \pm 1.5$ \\
C & $103.00 \mathrm{~b} \pm .05$ \\
$-\mathrm{C}-\mathrm{NPR}$ & $117.00 \mathrm{~b} \pm 1.5$ \\
\hline Means with the same letter are not significantly different $(\mathrm{P}>0.05)$.
\end{tabular}

Table 4: Cumulative dry matter weight (gm) under different levels of soil fertility management.

\begin{tabular}{lccccc}
\hline Treatments & \multicolumn{5}{c}{ Period of observation (weeks) } \\
\cline { 2 - 6 } & $\mathbf{0 ~ - 3}$ & $\mathbf{3 - 6}$ & $\mathbf{6 - 9}$ & $\mathbf{9 - 1 2}$ & $\mathbf{1 2}-\mathbf{1 5}$ \\
\hline T1 & $0.66 \pm .11$ & $1.73 \pm .25$ & $64.10 \pm .56$ & $8.16 \pm .35$ & $8.31 \pm .45$ \\
T2 & $7.78 \pm .05$ & $12.05 \pm .23$ & $21.49 \pm .35$ & $31.22 \pm .55$ & $31.95 \pm .55$ \\
T3 & $8.14 \pm .25$ & $14.35 \pm .05$ & $24.65 \pm .35$ & $33.18 \pm .51$ & $33.85 \pm .35$ \\
T4 & $18.9 \pm .12$ & $25.98 \pm .32$ & $44.05 \pm .51$ & $41.95 \pm 35$ & $54.92 \pm .51$ \\
\hline
\end{tabular}

Table 5: Relative growth rate (RGR) in $\mathrm{cm}$ of $R$. heudelotii under different levels of soil fertility management.

\begin{tabular}{lccccc}
\hline \multirow{2}{*}{ Treatments } & \multicolumn{5}{c}{ Period of observation (weeks) } \\
\cline { 2 - 6 } & $\mathbf{0 ~ - 3}$ & $\mathbf{3 - 6}$ & $\mathbf{6 - 9}$ & $\mathbf{9 - 1 2}$ & $\mathbf{1 2} \mathbf{- 1 5}$ \\
\hline T1 & $-0.16 \pm .15$ & $0.39 \pm .55$ & $0.33 \pm .33$ & $0.16 \pm .33$ & $0.28 \pm .51$ \\
T2 & $0.30 \pm .35$ & $0.26 \pm .35$ & $0.25 \pm .15$ & $0.22 \pm .35$ & $0.22 \pm .25$ \\
T3 & $0.27 \pm .55$ & $0.25 \pm .15$ & $0.22 \pm .25$ & $0.21 \pm .51$ & $0.21 \pm .35$ \\
T4 & $0.29 \pm .15$ & $0.28 \pm .25$ & $0.23 \pm 71$ & $0.21 \pm . .25$ & $0.22 \pm .23$ \\
\hline
\end{tabular}

Table 6: Net assimilation rate (NAR) in $\mathrm{gm} / \mathrm{cm}^{2} /$ week of $R$. heudelotii under different levels of soil fertility management.

\begin{tabular}{lcccc}
\hline Treatments & \multicolumn{4}{c}{ Period of observation (weeks) } \\
\cline { 2 - 5 } & $\mathbf{3 - 6}$ & $\mathbf{6 - 9}$ & $\mathbf{9 - 1 2}$ & $\mathbf{1 2} \mathbf{- 1 5}$ \\
\hline T1 & $-55.23 \pm 15$ & $15.19 \pm .05$ & $16.40 \pm .45$ & $59.67 \pm .51$ \\
T2 & $8.00 \pm .56$ & $26.89 \pm .15$ & $45.50 \pm .21$ & $274.08 \pm .35$ \\
T3 & $7.02 \pm .32$ & $-184.23 \pm .52$ & $41.12 \pm .34$ & $190.94 \pm .05$ \\
T4 & $38.66 \pm .12$ & $41.03 \pm .15$ & $35.20 \pm .25$ & $84.41 \pm .61$ \\
\hline
\end{tabular}


Table 7: Mean values of shoot and root dry weight, NAR and RGR of $R$. heudelotii plants that received compost and manure.

\begin{tabular}{lccc}
\hline Treatments & $\begin{array}{c}\text { Shoot +root dry } \\
\text { weight }\end{array}$ & NAR & RGR \\
\hline C+NPK & $8.31 \pm .45$ & $59.67 \pm 1.5$ & $0.86 \pm .55$ \\
C & $31.95 \pm .33$ & $274.08 \pm .25$ & $0.66 \pm .35$ \\
NPK & $33.85 \pm .25$ & $190.94 \pm .15$ & $0.64 \pm 1.5$ \\
-C-NPK & $54.92 \pm .71$ & $84.41 \pm .51$ & $0.68 \pm .35$ \\
\hline
\end{tabular}

Table 8: Follow-up for mean effect on period of application of fertilizer/compost.

\begin{tabular}{cccccc}
\hline \multicolumn{7}{c}{ Main effect: period } \\
\hline \multicolumn{7}{c}{ Periods } & Mean & 1 & 2 & 3 \\
\hline 3 & $(1)$ & $8.87000 \pm .05$ & XXXX & & \\
12 & $(2)$ & $13.52750 \pm .12$ & XXXX & XXXX & \\
15 & $(5)$ & $28.62750 \pm .35$ & & XXXX & XXXX \\
\hline
\end{tabular}

Means falling under the same rows are not significantly different $(\mathrm{P}>0.05)$.

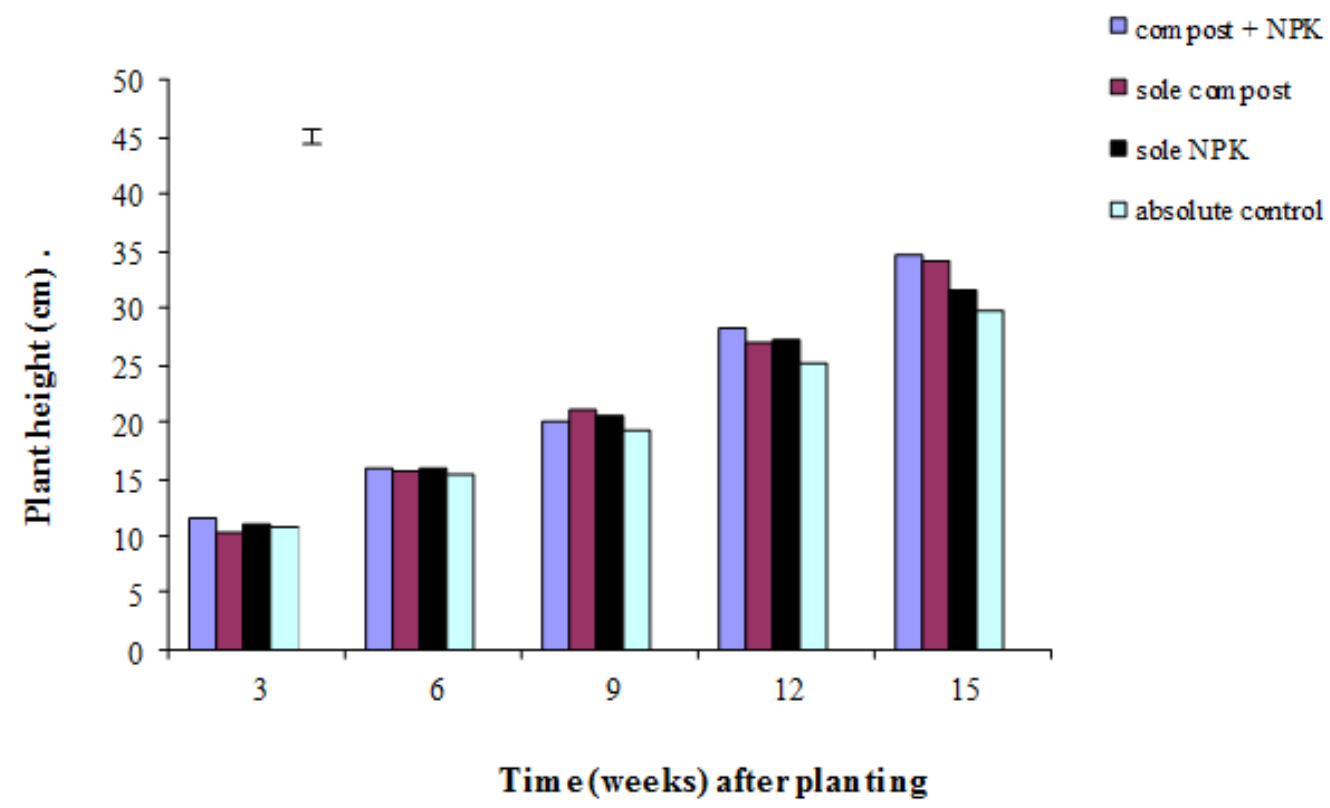

Figure 1: Effect of fertilizers and compost on plant height of $R$. heudelotii seedlings. 


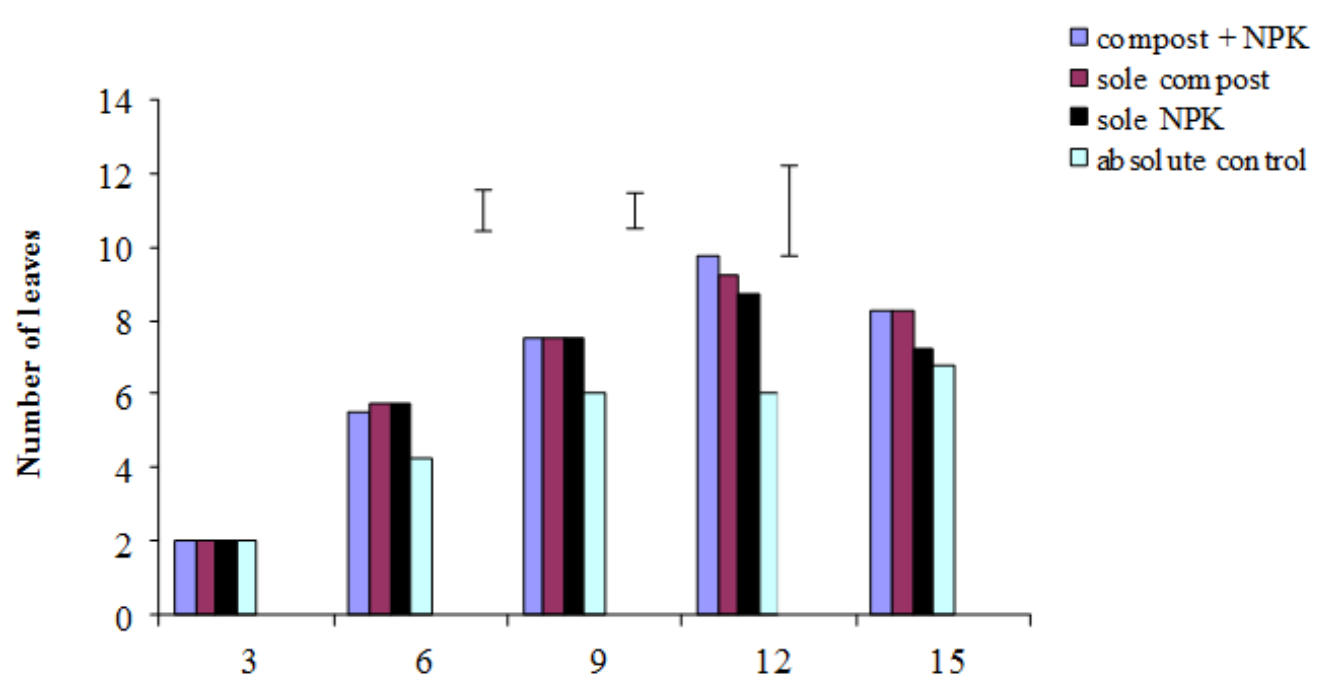

Time (weeks) after planting

Figure 2: Effect of fertilizers and compost on number of leaves per plant in $R$. heudelotii seedlings.

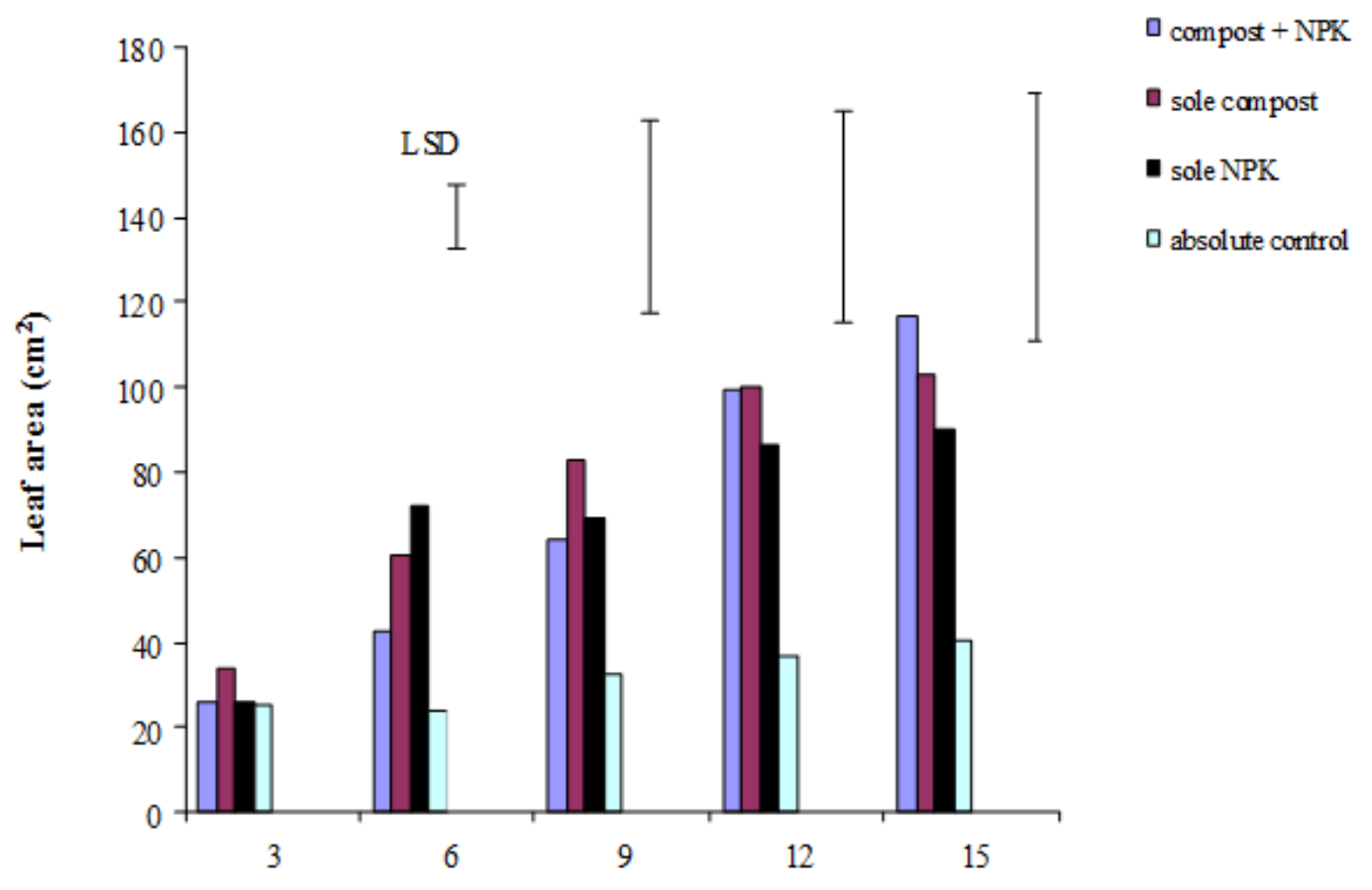

Time (weeks) after planting

Figure 3: Effect of fertilizers and compost on leaf area per plant in R. heudelotii seedlings. 


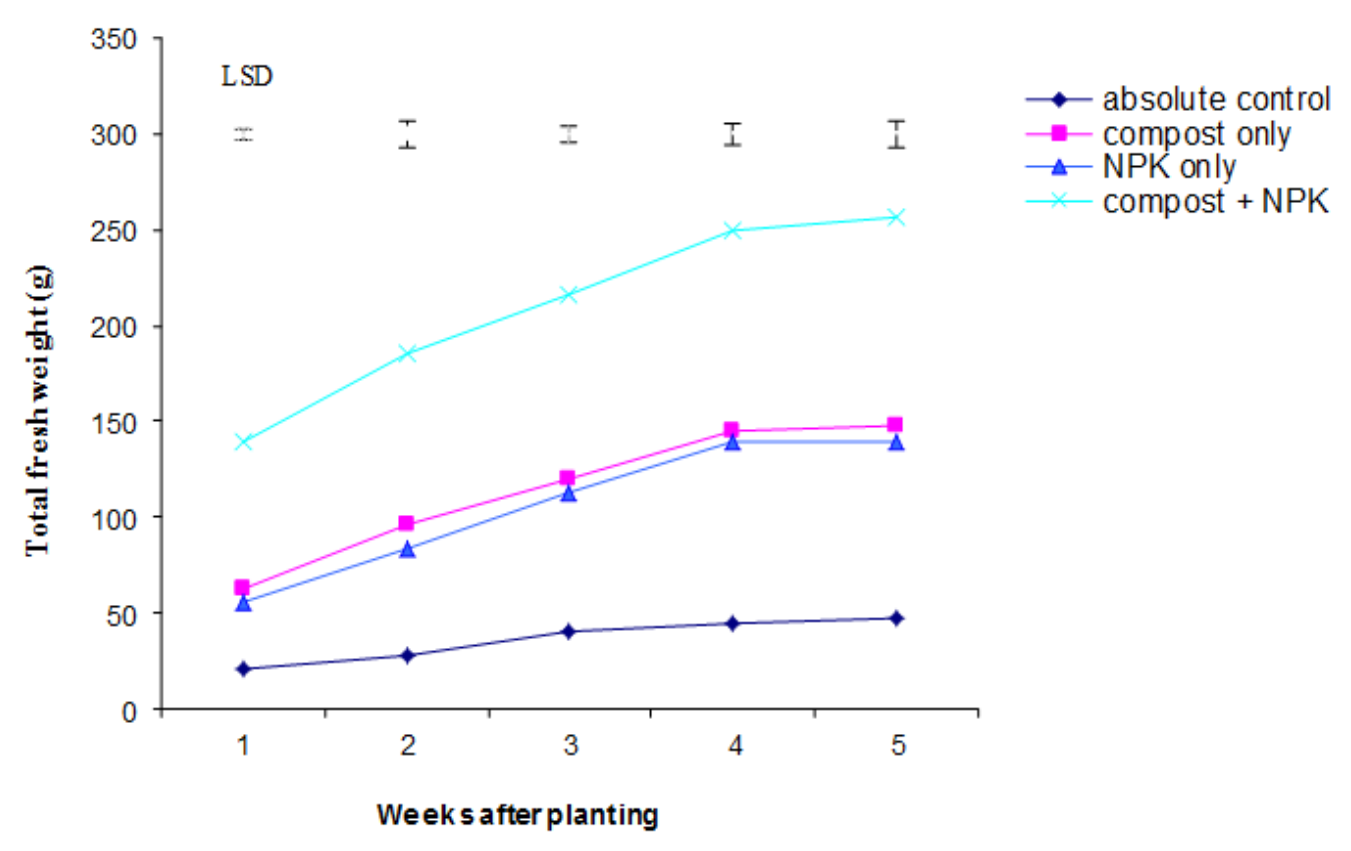

Figure 4: Effect of fertilizer and compost application on total fresh weight of $R$. heudelotii.

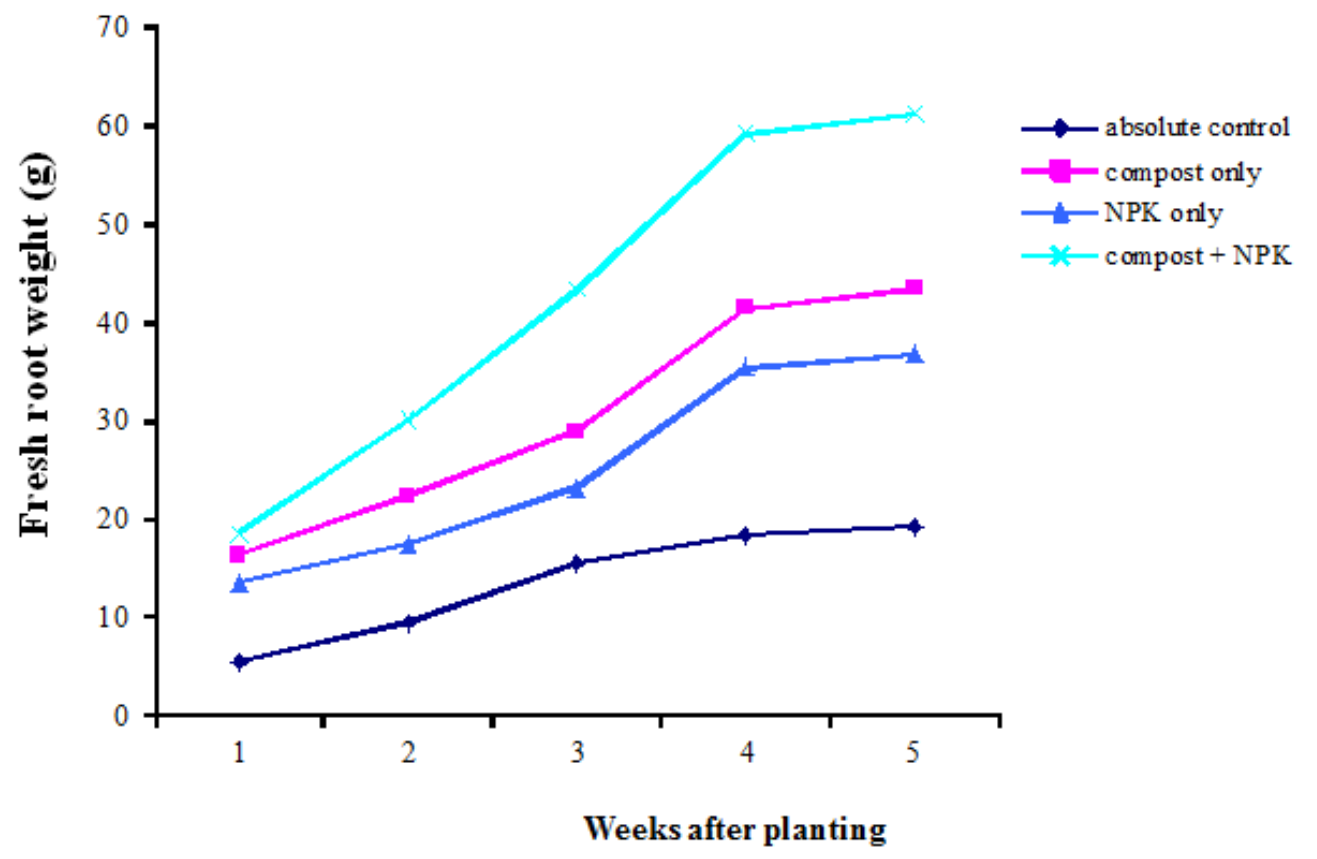

Figure 5: Effect of fertilizer and compost on fresh root weight of $R$. heudelotii. 


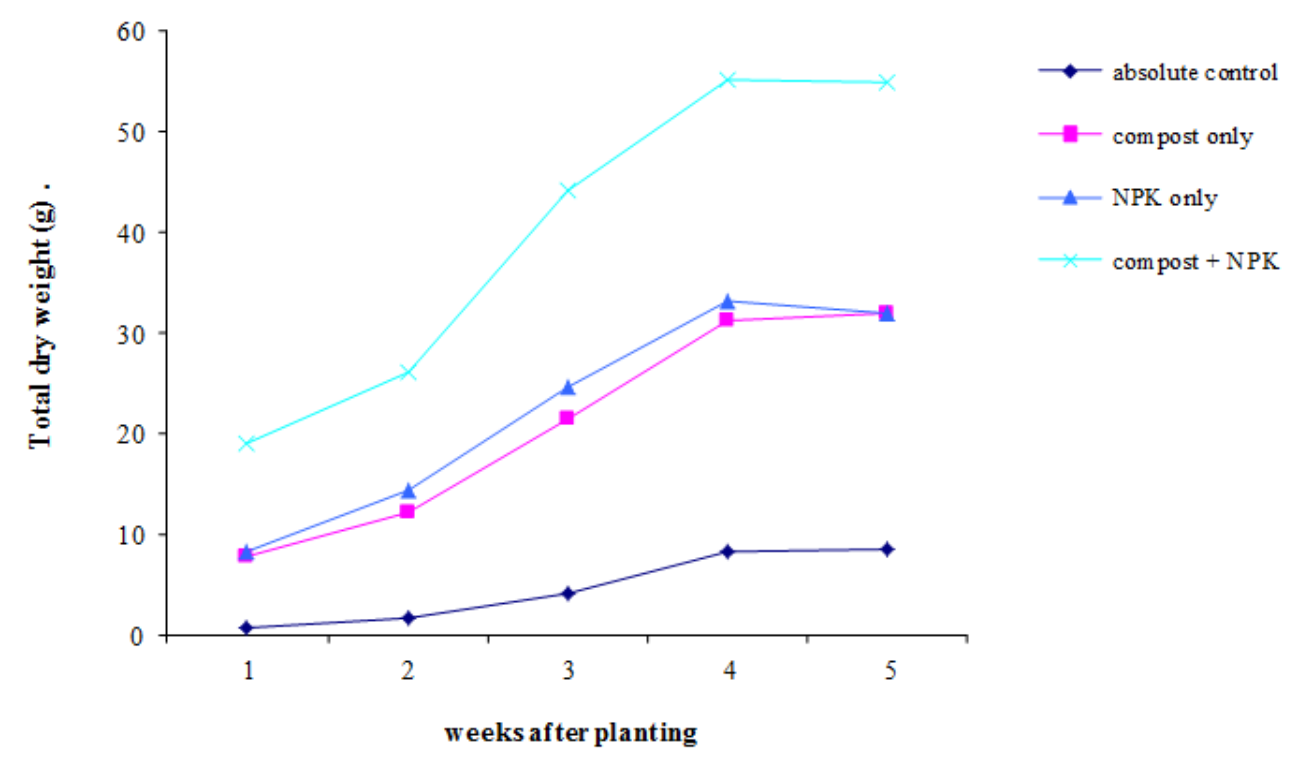

Figure 6: Effect of fertilizer and compost on total dry weight of $R$. heudelotii.

\section{DISCUSSION}

The higher vigorous growth (reflected in plant height, number of leaves and total biomass) of $R$. heudelotii under treatments (compost, NPK fertilizer, and NPK + compost) plots is a reflection of the need for augmenting soil fertility for forest regeneration practices as observed by (Lumu et al., 2013). Although forest soils are known to be rich in organic matter, decomposition is hindered by the conditions in the forest soil, such that these soils cannot supply the necessary nutrient required by the tree on demand (Bernard, 2015). These results confirm those of Catalina et al. (2010) as they observed no effect on fertilizer on the vegetative growth of coffee trees.

The performance of $R$. heudelotii under sole compost and compost + NPK fertilizer treatments was always comparable to or higher than sole NPK, indicating some synergistic effect with combined application of compost and NPK fertilizers. This agrees with Lumu et al. (2013). The results also confirm that of Taura and Fatima (2008) that the combination of organic manure and inorganic fertilizer have higher yields than either organic manure or inorganic fertilizer applied separately. A constraint with sole application of NPK is that some of the applied nutrients are leached Debora (2001). Consequently, loss of the nutrients would be available for tree uptake and leaching of nutrients is probably the biggest source of tree damage in acid soils. In addition, $P$ fixation is a common practice on acid soils.

When decomposition of organic matter is not favoured under conditions prevailing in the forest floor, less of the organic acids that are required to block P-fixing sites are produced, resulting in high fixation of applied P.

In recent years, the focus on soil fertility research has been on combining organic matter and mineral fertilizers as a way to arrest soil fertility decline in sub-Sahara Africa (Ndubuaku and Kassim, 2012). With combined application of mineral fertilizers and compost under conditions in the forest floor, mobilization of soil $\mathrm{N}$ and $\mathrm{P}$ by soil microorganisms is reduced and there is a build-up of organic carbon if organic matter is applied regularly, which provides a capital of nutrients that are slowly released, hence, agreeing with Bernard (2015). At the same 
time, the soil's buffering capacity for water, cations and acidity is increased.

\section{Conclusion}

Conclusively, rapid regeneration of $R$. heudelotii in forest soils of Menchum requires supplemental nutrients through organic and inorganic fertilizers applied at specific periods of 3.6 and 15 weeks. Experiments should therefore be designed to establish optimum levels of both compost, N, P and $\mathrm{K}$ to be applied as well as practices that reduce soil acidity. Combining both compost and NPK will improve on the rapid growth.

The optimum amount of nutrient required for optimum growth however is not known thus it is highly recommended that research geared towards this be conceived.

\section{ACKNOWLEDGEMENTS}

We wish to acknowledge the Head of the Laboratory of Soil and Environment laboratory of the University of Dschang for the enabling environment they provided during this work.

\section{REFERENCES}

Anjah GM, Oyun MB. 2009. Autecological study of Ricinodendron heudelotii (Baill) Pierre et Pax. in Agulli Forest. Int. J. Biol. Chem. Sci., 3(5): $1057-$ 1064.

Bernard N. 2015. Soils in forest zones with two rainy seasons. www//the Farmer's Voice.org/uk/focus

Catalina JB, Ricardo HS, Herminia EP, Martinez, Paulo RC, Merci PF. 2010. Production and vegetative growth of coffee trees under fertilization and shade levels. Sci. Agric. (Piracicaba, Braz.), 67(6): 639-645.
Deborah L. 2001. Nitrogen and phosphorus enhance growth and luxury consumption of four secondary forest tree species in Borneo. Journal of Tropical Ecology, 17: 859-869.

ICRAF.2004. http://worldagroforestry.org/ Sites/TreeDBS/aft/SpeciesPrinter riendly.asp? $\mathrm{Id}=1449$

Ndubuaku UM, Kassim A. 2012. Use of organic and inorganic fertilizers to improve the rate of cocoa seedling establishment in the field in Nigeria. Forests, Trees and Livelihood, 13: 101106.

Oni O, Gbadamasi AE. 1998. Progeny variations in seedlings of Dacryodes edulis G. Don. J. Trop. For. Res., 14: 38-47.

Lumu SK, Nyombi A, Swaga M, Bukeng H, Balimunsi S, Tumwebaze. 2013. Effect of native soil fertility and mineral fertilizer on growth of pine seedlings in Uganda. Ann. For. Res., 56(2): 283296.

Taura DW, Fatima MS. 2008. Effects of organic and inorganic fertilizers on the vegetative and reproductive parts of some selected varieties. African Journal of General Agriculture of cowpea (Vigna unguiculata), 4(2): 1595-6984.

Tchoundjeu Z, Atangana A. 2006. Ricinodendron heudelotii (Bail). Southampton Centre for Under-utilized Crops. University of Southampton: Southampton, UK; 74. 